\title{
A novel epitope-blocking ELISA for specific and sensitive detection of antibodies against $\mathrm{H} 5$-subtype influenza virus hemagglutinin
}

Violetta Sączyńska* (1), Katarzyna Florys-Jankowska, Anna Porębska and Violetta Cecuda-Adamczewska

\begin{abstract}
Background: H5-subtype highly pathogenic (HP) avian influenza viruses (AIVs) cause high mortality in domestic birds and sporadic infections in humans with a frequently fatal outcome, while H5N1 viruses have pandemic potential. Due to veterinary and public health significance, these HPAIVs, as well as low pathogenicity (LP) H5-subtype Alvs having a propensity to mutate into HP viruses, are under epidemiologic surveillance and must be reported to the World Organization for Animal Health (OIE). Our previous work provided a unique panel of 6 different monoclonal antibodies (mAbs) against $\mathrm{H} 5$ hemagglutinin ( $\mathrm{HA}$ ), which meets the demand for high-specificity tools for monitoring AlV infection and vaccination in poultry. In this study, we selected one of these mAbs to develop an epitope-blocking (EB) ELISA for detecting H5 subtype-specific antibodies in chicken sera (H5 EB-ELISA).

Methods: In the H5 EB-ELISA, H5 HA protein produced in a baculovirus-expression vector system was employed as a coating antigen, and the G-7-27-18 mAb was employed as a blocking antibody. The performance characteristics of the assay were evaluated by testing 358 sera from nonimmunized chickens and chickens immunized with AIVs of the $\mathrm{H} 1-\mathrm{H} 16$ subtypes or recombinant $\mathrm{H} 5 \mathrm{HA}$ antigen to obtain the reference and experimental antisera, respectively. The samples were classified as anti-H5 HA positive or negative based on the results of the hemagglutination inhibition (HI) assay, the gold standard in subtype-specific serodiagnosis.
\end{abstract}

Results: The H5 EB-ELISA correctly discriminated between the anti-H5 HA negative sera, including those against the non-H5 subtype AIVs, and sera positive for antibodies against the various-origin H5 HAs. Preliminary validation showed $100 \%$ analytical and $97.6 \%$ diagnostic specificities of the assay and $98.0 \%$ and $99.1 \%$ diagnostic sensitivities when applied to detect the anti-H5 HA antibodies in the reference and experimental antisera, respectively.

Conclusions: The H5 EB-ELISA performed well in terms of diagnostic estimates. Thus, further optimization and validation work using a larger set of chicken sera and receiver operating characteristic (ROC) analysis are warranted. Moreover, the present assay provides a valuable basis for developing multispecies screening tests for birds or diagnostic tests for humans.

Keywords: Avian influenza viruses, Hemagglutinin, Monoclonal antibodies, Antibody detection, Blocking ELISA, H5, Serology

*Correspondence: saczynskav@iba.waw.pl; Violetta.Saczynska@ichp.pl

ŁUKASIEWICZ Research Network - Industrial Chemistry Institute,

Rydygiera 8 Street, 01-793 Warsaw, Poland original author(s) and the source, provide a link to the Creative Commons licence, and indicate if changes were made. The images or other third party material in this article are included in the article's Creative Commons licence, unless indicated otherwise in a credit line to the material. If material is not included in the article's Creative Commons licence and your intended use is not permitted by statutory regulation or exceeds the permitted use, you will need to obtain permission directly from the copyright holder. To view a copy of this licence, visit http://creativecommons.org/licenses/by/4.0/. The Creative Commons Public Domain Dedication waiver (http://creativeco mmons.org/publicdomain/zero/1.0/) applies to the data made available in this article, unless otherwise stated in a credit line to the data. 


\section{Background}

Influenza viruses (IVs) belong to the Orthomyxoviridae family, which consists of seven genera [1]. Strains of the most epidemiologically relevant influenza $A$ virus species of the Alphainfluenzavirus genus are enveloped negative-sense single-strand RNA viruses with a segmented genome [2]. Eight RNA segments encode RNA polymerase subunits, nucleoprotein (NP), matrix protein (M1) and membrane protein (M2), nonstructural protein (NS1) and nuclear export protein (NEP), and surface glycoproteins, hemagglutinin (HA) and neuraminidase (NA). Influenza A viruses have antigenically related NP and M1 proteins [3]. They are classified into subtypes on the basis of their variable HA and NA antigens. A total of 16 HA subtypes (H1-H16) and 9 NA subtypes (N1N9) have been identified in wild aquatic birds, the major reservoir of influenza A viruses. Avian influenza viruses (AIVs) are usually nonpathogenic in their natural waterfowl hosts, and most of them are of low pathogenicity (LP) for domestic birds. However, the H5- and H7-subtype AIVs may become highly pathogenic (HP) by mutation once introduced into the poultry population.

HPAIVs caused sporadic epizootics in domestic poultry until 1996 [4]. Since then, the H5N1 HPAIV has become enzootic in poultry within several countries. Concomitant with the initial circulation and spread of the H5N1 viruses, HA genes diversified into multiple genetic lineages, termed clades [5]. In 2008, substantial reassortment events began and resulted in the creation of a range of $\mathrm{H} 5 \mathrm{Nx}$ reassortants, such as H5N2, H5N6 and H5N8 HPAIVs, that have acquired novel NA proteins [6]. Emerging outbreaks of disease evoked by H5-subtype HPAIVs are accompanied by high virulence and mortality among domestic birds, which leads to enormous economic losses for the poultry industry [5, 6]. Moreover, the $\mathrm{H} 5 \mathrm{~N} 1$ and $\mathrm{H} 5 \mathrm{~N} 6$ strains of the virus cause sporadic infections in humans [6], and fatal cases of human infection with $\mathrm{H} 5 \mathrm{~N} 1$ viruses are still noted [7]. The important issue is the pandemic potential of H5N1 HPAIVs. Due to the threat to animal and human health and life, H5-subtype HPAIVs are under epidemiologic surveillance [3]. LPAIVs of the $\mathrm{H} 5$ subtype are also a serious concern, as they have the potential to mutate into HP viruses. Accordingly, the occurrence of both the HP and LP H5Nx viruses must be reported to the World Organization for Animal Health (OIE). Therefore, all of the H5-subtype viruses are classified as notifiable AIVs (NAIVs).

Research on the evolution, spreading and occurrence of novel strains of H5Nx AIVs requires specific and reliable methods for virus and antibody detection, subtype identification and pathotype classification [4] that are prescribed by the OIE [3]. In early influenza diagnostics, influenza virus is detected primarily using the real-time reverse transcriptase polymerase chain reaction (rRT-PCR) assay, virus isolation and antigen immunoassays. Subsequently, the subtype of the virus may be identified with rRT-PCR or sequencing the HA and NA genes and pathotype of the $\mathrm{H} 5$ or $\mathrm{H} 7$ subtype virus by in vivo chicken testing and determining the sequence of the HA proteolytic cleavage site. To assess prior exposure to AIVs, serological diagnosis of influenza is performed using the two-step procedure. The detection of antibodies to any AIV is followed by identification of the virus subtype. Detecting the antibodies to the group antigens of influenza A viruses, the NP and/or M1 proteins, is routinely accomplished using the agar gel immunodiffusion (AGID) test and enzymelinked immunosorbent assay (ELISA). For determination of the HA and NA subtypes, hemagglutination inhibition (HI) and neuraminidase inhibition (NI) tests are recommended, respectively. The general assessment of the current tests for most AIV testing is that they are adequate, while some modifications, updates or additional tests would be beneficial [4]. The element of AIV diagnostics that is the most in need of improvement is in determining the HA and NA subtype specificity of antibodies to AIV.

In subtype-specific serodiagnosis, the $\mathrm{HI}$ test is considered to be the 'gold standard' [8]. Its accuracy can be near perfect, however, only when the reference viral antigen is close enough to the virus isolate to be tested. To avoid the risk of false negative results, a panel of different antigens should be used in the initial analyses. The issues that need to be considered while performing the $\mathrm{HI}$ test are also nonspecific hemagglutination and nonspecific inhibition of hemagglutination [3]. They may be circumvented by sample pretreatment and using at least two antigens of the same HA subtype but with different NA subtypes. The assays require several control samples. Thus, the HI test is demanding with respect to the protocol, reagents and interpretation. Moreover, it is laborintensive, time-consuming and difficult to automate, which restricts its use in large-scale sero-surveillance studies. Due to substantial limitations of the HI assay, subtype-specific ELISAs in competitive and blocking formats (cELISA and bELISA, respectively) have been developed as high-throughput screening tests [8]. Their accuracy has in most cases been evaluated in reference to the HI test. Currently, some subtype-specific ELISA kits are becoming available such as kits for antibodies to H5 and H7 HAs and N1 NA [3]. In addition to serodiagnosis, such kits may be successfully used in AIV vaccination programs for differentiating infected animals from vaccinated animals as so-called DIVA tests. In cELISAs and bELISAs, subtype-specific monoclonal antibodies (mAbs) are employed as essential reagents. 
Diversity of the H5-subtype AIVs and continual variability of HA antigens are objective difficulties and simultaneously a challenge in serodiagnosis and surveillance of these viruses. In particular, the development of diagnostically valuable cELISA or bELISA tests requires the use of $\mathrm{mAbs}$ recognizing intrasubtype-conserved epitopes in the HA antigen. This requirement is met by the highly and broad-range specific mAbs against $\mathrm{H} 5 \mathrm{HAs}$, which were produced and differentiated by us according to the procedures presented previously, together with the results from immunoreactivity studies [9]. In this work, the diagnostic value of the newly generated mAbs was positively verified by using one of the 6 antibody clones, the G-7-27-18 mAb, in epitope-blocking (EB) ELISA for detecting $\mathrm{H} 5$ subtype-specific antibodies in chicken sera. Here, the current characteristics of the developed test, referred to as H5 EB-ELISA, are shown, and its future prospects are discussed.

\section{Methods}

\section{MAb production and selection}

MAbs against H5 HA were generated according to the procedure described previously [9]. Briefly, five 6-weekold female $B A L B / c$ mice were immunized with purified recombinant $\mathrm{H} 5 \mathrm{HA}$ protein produced in a mammalian expression system (Immune Technology Corp., New York, NY, USA). Details of the protein, referred to as rH5-mammalian, are provided in Additional file 1: Table S1. The first 10- $\mu$ g dose of immunogen, emulsified with an equal volume of complete Freund's adjuvant (Sigma-Aldrich, St. Louis, MO, USA), was administered subcutaneously. The booster doses, each containing $10 \mu \mathrm{g}$ of $\mathrm{rH} 5$-mammalian in PBS, were given twice by intraperitoneal injection and once intravenously. Three days after the last immunization, splenocytes were isolated and fused with mouse myeloma of the SP2/0 cell line (ATCC, Rockville, MD, USA). The fused hybrid cells were cultured in RPMI-1640 medium containing FBS, L-glutamine, sodium pyruvate, and antibiotics, with hypoxanthine, aminopterin and thymidine (HAT) as the selecting agents. The hybridomas were subcloned by the limited dilution method. The resulting hybridoma cell lines were grown in RPMI-1640 medium with the same supplements as the selection culture medium except for HAT. The reagents used for fusion and hybridoma culture were purchased from Sigma-Aldrich.

The hybridoma culture supernatants were screened for the presence of IgG antibodies against H5 HA using ELISAs that targeted the various $\mathrm{H} 5 \mathrm{HA}$ antigens. They included proteins from a mammalian expression system (Immune Technology Corp.) and a baculovirus-expression vector system (Oxford Expression Technologies Ltd., Oxford, England, UK). In addition, inactivated,
H5-subtype AIVs (x-OvO Ltd., Dunfermline, Scotland, UK), certified by Istituto Zooprofilattico Sperimentale delle Venezie (IZSVe; Legnaro, Padova, Italy), were used. The sequences of the HA antigens employed in the positive hybridoma selection originated from the highly divergent H5-subtype influenza viruses. The selected mAbs, for a total of 7 clones, were purified from the hybridoma culture supernatants using a HiTrap Protein G HP column (GE Healthcare, Uppsala, Sweden).

\section{Analyses of selected mAbs}

The finally selected, affinity-purified mAbs, denoted G-1-31-22, G-2-14-10, G-5-32-5, G-6-42-42, G-6-42-71, G-7-24-17 and G-7-27-18, were characterized by isotyping, immunoreactivity studies and peptide mapping, as described previously [9]. Isotyping was performed using a commercial kit: 'Mouse Monoclonal Antibody Isotyping Reagents' (ISO-2; Sigma-Aldrich). The reactivity range of the selected mAbs was determined using ELISAs against well-characterized recombinant $\mathrm{H} 5 \mathrm{HA}$ proteins produced in mammalian or insect cells (Immune Technology Corp., Oxford Expression Technologies Ltd., respectively) and inactivated, $\mathrm{H} 5$-subtype AIVs (x-OvO Ltd.) certified by IZSVe (Legnaro, Padova, Italy). As a result, the $\mathrm{H} 5 \mathrm{HA}$ antigens varied in form (recombinant proteins or influenza viruses), length (HA fragments or full-length HAs), conformation (properly folded or misfolded), oligomerization state (monomeric or at least partly oligomeric) and glycosylation pattern (mammalian or insect). Conformational H5 HA antigens used in the specificity analyses included the sequences of 12 strains of HP or LP and H5-subtype AIVs. Consistently, they had diverse amino acid sequences, especially within the subtype-determining HA1 subunit, which was confirmed by a homology search against the immunogen (BLAST program, NCBI). To ascertain the cross-reactivity of the obtained mAbs, 21 strains of AIVs (x-OvO Ltd.) certified by IZSVe (Legnaro, Padova, Italy) were used for testing. They represented the $\mathrm{H} 1-\mathrm{H} 4$ and $\mathrm{H} 6-\mathrm{H} 16$ subtypes of influenza viruses. Apart from determination of the specificity range, the $\mathrm{mAb}$ examination by ELISAs comprised the binding capability assessment and immunoreactivity profiling. Peptide mapping was performed for the Fab and Fc antibody fragments digested with trypsin using a matrix-assisted laser desorption ionization time of flight (MALDI-TOF/TOF) mass spectrometer (Applied Biosystems, Waltham, MA, USA). On this basis, the profiles of the tryptic peptide maps of individual antibody clones were defined.

The newly generated antibodies against H5 HA were also subjected to the $\mathrm{HI}$ test with $\mathrm{H} 5 \mathrm{~N} 2$ and $\mathrm{H} 5 \mathrm{~N} 3$ LPAIVs ( $\mathrm{x}-\mathrm{OvO}$ Ltd.) as the reference antigens. Among the H5N1, H5N2, H5N3 and H5N9 AIVs previously 
employed in ELISAs for antibody specificity, the H5N2 virus had the lowest and the H5N3 virus the highest homology to the HA1 subunit of immunogen used in $\mathrm{mAb}$ production (Additional file 1: Table S6). In the test, the reference anti-H5N2, anti-H5N3 and anti-H7N7 LPAIV antisera ( $\mathrm{x}-\mathrm{OvO}$ Ltd.) as well as commercial mAbs against H5 HA (Acris Antibodies GmbH, Herford, Germany; Pierce/Thermo Fisher Scientific, Waltham, MA, USA) served as positive or negative controls (Additional file 2: Tables S1 and S2). The test was performed using erythrocytes of specific pathogen-free (SPF) chickens obtained from the Department of Poultry Diseases, National Veterinary Research Institute (DPD NVRI, Puławy, Poland). Details are provided in Additional file 2.

\section{Serum samples}

A panel of 358 chicken serum samples comprised the anti-LPAIV reference antisera, experimental antisera specific for $\mathrm{H} 5 \mathrm{HA}$ and anti-H5 HA negative sera. HA antigens used to obtain the antiserum samples had sequences derived from a total of 26 virus strains.

Reference antisera, certified by IZSVe (Legnaro, Padova, Italy), were purchased from $\mathrm{x}$-OvO Ltd. They were produced in the SPF chickens inoculated with 25 strains of inactivated LPAIVs representing the HA subtypes from $\mathrm{H} 1$ to $\mathrm{H} 16$. The H5-subtype viruses used for chicken immunization were $\mathrm{H} 5 \mathrm{~N} 1, \mathrm{H} 5 \mathrm{~N} 2, \mathrm{H} 5 \mathrm{~N} 3$ and H5N9 LPAIVs. In this work, 1, 2 or 3 batches of each anti-AIV antiserum were used. Consistently, the set of reference antisera comprised 31 samples. The presence of subtype-specific antibodies in these samples was confirmed by $\mathrm{HI}$ assays with homologous virus strains. The values of $\mathrm{HI}$ titers were included in the product certificates.

Experimental antisera were from previously presented efficacy trials for the HA protein of the H5N1 HPAIV produced in Escherichia coli [10]. The vaccine antigen, referred to as rH5-E. coli, was refolded and chromatographically purified from inclusion bodies. Immunization studies were performed in the Rossa 1 line of layer chickens. The chickens were purchased from a commercial breeder on the day of hatching and maintained at an experimental poultry house with wheat straw bedding. Vaccines dedicated for commercial flocks were not administered. Eight groups of 3-week-old layers were vaccinated twice with $25 \mu \mathrm{g}, 15 \mu \mathrm{g}, 10 \mu \mathrm{g}$, or $5 \mu \mathrm{g}$ of rH5E. coli and aluminum hydroxide (alum) adjuvant. In this work, a total of 115 samples collected 1 and/or 2 weeks after the boost were used.

The anti-H5 HA negative sera were from control groups in the immunization studies with rH5-E. coli, including those reported previously [10]. The studies were performed under semifield conditions, described above, using the commercial layers and broilers-namely, the Rossa 1 and Ross 308 lines, respectively. Samples were collected from the nonimmunized chickens at different time points of the experiments. Thus, the obtained panel of 191 samples negative for H5 HA was completed with 18 sera from SPF layers, the White Leghorn line (DPD NVRI, Puławy, Poland), and 1 batch of normal chicken serum (Abcam, Cambridge, England, UK).

Serum samples and their applications in the development and evaluation of EB-ELISA are described in Table 1. Influenza virus strains used to obtain reference antisera against $\mathrm{H} 5$ and non- $\mathrm{H} 5$ subtype AIVs are listed in Additional file 1: Tables S2 and S3, respectively, together with other details of serum samples. Supplementary data on the vaccine antigen, rH5-E. coli, and the anti-H5 HA experimental antisera are provided in Additional file 1: Tables S1 and S4, respectively.

\section{Hemagglutinin inhibition (HI) assay}

$\mathrm{HI}$ activity was determined for sera from commercial chickens immunized and nonimmunized with rH5-E. coli, as indicated in Table 1. The reference viral antigen and antisera used in the $\mathrm{HI}$ assay were from $\mathrm{x}-\mathrm{OvO} \mathrm{Ltd}$. Details are provided in Additional file 1: Table S5. Normal chicken serum (Table 1) was analyzed using reference reagents from the Veterinary Laboratories Agency (New Haw, England, UK).

The HI assay was performed according to the OIE Manual of Diagnostic Tests and Vaccines for Terrestrial Animals [11] following the previously described procedure [10]. Briefly, the sera were analyzed with the heterologous A/turk/Italy/80(H5N2) LPAIV strain at an HI unit (HIU) of 1:8 using SPF chicken erythrocytes (DPD NVRI, Puławy, Poland). Each assay included control erythrocytes, the antiserum against H5N2 LPAIV as a positive control and anti-H7N4 and/or anti-H7N7 LPAIV antisera as negative controls. The HI titer was defined as the reciprocal of the highest dilution of serum that caused an inhibition of hemagglutination activity with 4 hemagglutination units (HAU) of the inactivated antigen. In this study, serum $\mathrm{HI}$ titers equal to or greater than 1:8 were considered positive. On this basis, each serum sample was scored as positive or negative for H5 subtypespecific antibodies. The results of the HI assay for 115 antisera collected in the layers immunized with rH5-E. coli and 96 sera from the nonimmunized layers and broilers were adapted from our previous paper [10].

\section{Epitope-blocking ELISA (EB-ELISA)}

EB-ELISA was performed using the purified recombinant H5 HA protein (aa 17-530, $\triangle$ RRRKKR, $6 \times$ His) produced in a baculovirus-expression vector system (BEVS; Oxford Expression Technologies Ltd.). Details 
Table 1 Sera used for H5 EB-ELISA development and preliminary validation

\begin{tabular}{|c|c|c|c|c|c|}
\hline Chickens & Immunogen & Serum description & Samples (N) & HI titer & Origin \\
\hline \multicolumn{6}{|c|}{ Anti-H5 HA positive (1): reference antisera against LPAIVs of the $\mathrm{H} 5$ subtype } \\
\hline \multicolumn{6}{|c|}{ Used in evaluation of diagnostic sensitivity 1 (Dse 1) } \\
\hline SPF & H5N1 AIV, inactivated & One batch (\#1) & 1 & $\begin{array}{l}\text { 1:512 with H5N1 AIV accord- } \\
\text { ing to the certificate }\end{array}$ & $x-O v O$ Ltd. $^{1 a}$ \\
\hline SPF & H5N2 AIV, inactivated & $\begin{array}{l}\text { Three batches (\#1, \#2 and } \\
\text { \#3) }\end{array}$ & 3 & $\begin{array}{l}1: 256 \text { or } 1: 512 \text { with } \mathrm{H} 5 \mathrm{~N} 2 \\
\text { AIV according to the } \\
\text { certificates }\end{array}$ & $\mathrm{x}-\mathrm{OvO} \mathrm{Ltd}^{1 \mathrm{a}}$ \\
\hline SPF & H5N3 AIV, inactivated & $\begin{array}{l}\text { Three batches (\#1, \#2 and } \\
\text { \#3) }\end{array}$ & 3 & $\begin{array}{l}\text { 1:512 with H5N3 AIV accord- } \\
\text { ing to the certificates }\end{array}$ & $x-O v O$ Ltd. $^{1 a}$ \\
\hline SPF & H5N9 AIV, inactivated & Two batches (\#1 and \#2) & 2 & $\begin{array}{l}\text { 1:512 or } 1: 256 \text { with } \mathrm{H} 5 \mathrm{~N} 9 \\
\text { AIV according to the } \\
\text { certificates }\end{array}$ & $x-O v O$ Ltd. $^{1 a}$ \\
\hline \multicolumn{6}{|c|}{ Positive controls (PC) used for repeatability determination } \\
\hline SPF & H5N2 AIV, inactivated & Batch \#3 (weak PC) & 1 & $\begin{array}{l}\text { 1:512 with H5N2 AlV accord- } \\
\text { ing to the certificate }\end{array}$ & $x-O v O$ Ltd. $^{1 a}$ \\
\hline SPF & H5N3 AIV, inactivated & Batch \#1 (strong PC) & 1 & $\begin{array}{l}\text { 1:512 with H5N3 AIV accord- } \\
\text { ing to the certificate }\end{array}$ & $\mathrm{x}-\mathrm{OvO}$ Ltd. $^{1 \mathrm{a}}$ \\
\hline \multicolumn{6}{|c|}{ Anti-H5 HA positive (2): experimental antisera against HA from H5N1 HPAIV } \\
\hline \multicolumn{6}{|c|}{ Used in evaluation of diagnostic sensitivity 2 (Dse 2) } \\
\hline $\begin{array}{l}\text { Commercial layers, Rossa } \\
1 \text { line }\end{array}$ & $\begin{array}{l}\text { rH5-E. coli adjuvanted with } \\
\text { alum }\end{array}$ & $\begin{array}{l}\text { From } 69 \text { chickens at } 8,9,10 \\
\text { or } 11 \text { weeks of age; } 1 \text { or } 2 \\
\text { sampling time points per } \\
\text { chicken }\end{array}$ & $115(115)$ & $\begin{array}{l}\text { 1:8-1:512 with H5N2 AIV, } \\
\text { determined at IBA }\end{array}$ & $\mathrm{IBA}^{2 \mathrm{a}}$ \\
\hline \multicolumn{6}{|c|}{ Anti-H5 HA negative (1): sera of various origin } \\
\hline \multicolumn{6}{|c|}{ Used in determination of cutoff value and diagnostic specificity (Dsp) } \\
\hline $\begin{array}{l}\text { SPF layers, White Leghorn } \\
\text { line }\end{array}$ & None & $\begin{array}{l}\text { From } 10 \text { chickens at } 9 \text { or } \\
11 \text { weeks of age; } 1 \text { or } 2 \\
\text { sampling time points per } \\
\text { chicken }\end{array}$ & 18 & Negative Al status & DPD NVRI $\left.\right|^{3}$ \\
\hline $\begin{array}{l}\text { Commercial layers, Rossa } \\
1 \text { line }\end{array}$ & None & $\begin{array}{l}\text { From } 30 \text { chickens at } 7,8,9, \\
10 \text { or } 11 \text { weeks of age; } 3-5 \\
\text { sampling time points per } \\
\text { chicken }\end{array}$ & $130(63)$ & $\begin{array}{l}<1: 8 \text { with H5N2 AIV, deter- } \\
\text { mined at IBA }\end{array}$ & $\mathrm{IBA}^{2 \mathrm{~b}}$ \\
\hline $\begin{array}{l}\text { Commercial broilers, Ross } \\
308 \text { line }\end{array}$ & None & $\begin{array}{l}\text { From } 42 \text { chickens at } 3,5,5 \\
1 / 2,6 \text { or } 7 \text { weeks of age; } 1-4 \\
\text { sampling time points per } \\
\text { chicken }\end{array}$ & $61(33)$ & $\begin{array}{l}<1: 8 \text { with } \mathrm{H} 5 \mathrm{~N} 2 \text { AIV, deter- } \\
\text { mined at IBA }\end{array}$ & $\mathrm{IBA}^{2 \mathrm{~b}}$ \\
\hline \multicolumn{6}{|c|}{ Negative control (NC) used for repeatability determination } \\
\hline Different strains and sex & None & $\begin{array}{l}\text { Normal chicken serum, } 1 \\
\text { batch (NC) }\end{array}$ & 1 & $\begin{array}{l}<1: 8 \text { with } \mathrm{H} 5 \mathrm{~N} 2 \text { AIV, deter- } \\
\text { mined at IBA }\end{array}$ & Abcam $^{4}$ \\
\hline \multicolumn{6}{|c|}{ Anti-H5 HA negative (2): reference antisera against LPAIVs of the non-H5 subtypes } \\
\hline \multicolumn{6}{|c|}{ Used in evaluation of analytical specificity (Asp) } \\
\hline SPF & $\begin{array}{l}\text { AIVs: } \mathrm{H} 1-\mathrm{H} 4, \mathrm{H} 6-\mathrm{H} 12 \text { and } \\
\mathrm{H} 14-\mathrm{H} 16 \text { inactivated }\end{array}$ & $\begin{array}{l}\text { One batch of each antise- } \\
\text { rum }\end{array}$ & 20 & $\begin{array}{l}\text { 1:128-1:2048 with homolo- } \\
\text { gous AIVs according to the } \\
\text { certificates }\end{array}$ & $x-O v O$ Ltd. $^{1 b}$ \\
\hline SPF & H13N6 AIV, inactivated & Two batches (\#1 and \#2) & 2 & $\begin{array}{l}\text { 1:128 or } 1: 1024 \text { with } \mathrm{H} 13 \mathrm{~N} 6 \\
\text { AIV according to the } \\
\text { certificates }\end{array}$ & $x-O v O$ Ltd. $^{1 b}$ \\
\hline
\end{tabular}

\footnotetext{
${ }^{1}$ Certified by Istituto Zooprofilattico Sperimentale delle Venezie (IZSVe; Legnaro, Padova, Italy) and purchased from x-OvO Ltd. (Dunfermline, Scotland, UK). Details of reference antisera against (a) $\mathrm{H} 5$ and (b) non- $\mathrm{H} 5$ subtype AIVs are provided in Additional file 1: Tables S2 and S3, respectively

${ }^{2}$ Collected in (a) the test vaccine and (b) control chicken groups during immunization studies with $\mathrm{H} 5 \mathrm{HA}$ protein produced in bacteria ( $\mathrm{rH} 5$ - $E$. coli) at the Institute of Biotechnology and Antibiotics (IBA; Warsaw, Poland). The number of samples described previously with HI titers [10] are provided in brackets. Details of the vaccine antigen and experimental antisera against $\mathrm{H} 5 \mathrm{HA}$ are presented in Additional file 1: Tables S1 and S4, respectively

${ }^{3}$ Obtained from the Department of Poultry Diseases, National Veterinary Research Institute (DPD NVRI; Puławy, Poland)

${ }^{4}$ (Cambridge, England, UK), Cat. No. b7477
} 
of the protein, referred to as $\mathrm{HH} 5$-BEVS, are provided in Additional file 1: Table S1. The MediSorp plates (Nunc, Roskilde, Denmark) were coated by overnight incubation at $2-8{ }^{\circ} \mathrm{C}$ with $50 \mu \mathrm{L} /$ well of rH5-BEVS at a concentration of $0.5 \mu \mathrm{g} / \mathrm{mL}$ in PBS. The coated plates were washed three times with $300 \mu \mathrm{L} /$ well of PBS containing $0.05 \%$ Tween 20 (PBST; pH 7.4) and then incubated with $200 \mu \mathrm{L} /$ well of Protein-Free T20 (PBS) Blocking Buffer (Pierce/Thermo Fisher Scientific) for $1 \mathrm{~h}$ at room temperature $\left(23 \pm 2{ }^{\circ} \mathrm{C}\right)$. After washing two times with $350 \mu \mathrm{L} /$ well of PBST, incubation buffer (1\% BSA in PBS) was applied to the plates at $50 \mu \mathrm{L}$ or $100 \mu \mathrm{L}$ per well. Sera at $50-\mu \mathrm{L}$ volumes were added to the wells with $50 \mu \mathrm{L}$ of incubation buffer, resulting in a twofold sample dilution. The wells with $100 \mu \mathrm{L}$ of incubation buffer were left without the serum addition to provide a control of maximum mAb binding to rH5-BEVS (mAb control). Each assay for the test sera, listed in Table 1, was performed in the presence of other control samples. The anti-H5N2 and anti-H5N3 LPAIV antisera were the weak and strong positive controls, respectively (Table 1, Additional file 1: Table S2), while the normal chicken serum (Table 1) was a negative control. All sera were analyzed in duplicate. The plates with test and control samples were incubated for $1 \mathrm{~h}$ at $37^{\circ} \mathrm{C}$ with shaking at $150 \mathrm{rpm}$ and subsequently washed three times with $300 \mu \mathrm{L} /$ well of PBST. Next, $50 \mu \mathrm{L} /$ well of G-7-27-18 mAb, diluted to $1 \mu \mathrm{g} / \mathrm{mL}$ in Antibody Stabilizer PBS (CANDOR Bioscience GmbH, Wangen, Germany), was applied to the plates, which were then incubated again for $1 \mathrm{~h}$ at $37{ }^{\circ} \mathrm{C}$ with shaking at $150 \mathrm{rpm}$ and washed three times with $300 \mu \mathrm{L} /$ well of PBST afterwards. Antigen-bound mAbs were detected using HRP-labeled, anti-mouse IgG $(\gamma$-chain specific) antibodies (Sigma-Aldrich). The plates were incubated with $50 \mu \mathrm{L} /$ well of anti-mouse antibodies, diluted 1:3,500 in HRP-Protector (CANDOR Bioscience $\mathrm{GmbH}$ ), for $1 \mathrm{~h}$ at $37^{\circ} \mathrm{C}$ with shaking at $150 \mathrm{rpm}$ and then washed three times with $300 \mu \mathrm{L} /$ well of PBST. The reactions were developed with $50 \mu \mathrm{L} /$ well of TMB (Sigma-Aldrich) at room temperature $\left(25 \pm 0.1{ }^{\circ} \mathrm{C}\right)$ in the dark for $15 \mathrm{~min}$ and subsequently stopped by adding $50 \mu \mathrm{L} /$ well of $0.5 \mathrm{M} \mathrm{H}_{2} \mathrm{SO}_{4}$.

The optical density (OD) was measured at $450 \mathrm{~nm}$ $\left(\mathrm{OD}_{450}\right)$ using a Synergy 2 multidetection microplate reader (BioTek Instruments Inc., Winooski, VT, USA). For each test and control sample, the mean $\mathrm{OD}_{450}$ value was calculated. The reduction of $\mathrm{mAb}$ binding to $\mathrm{rH} 5$-BEVS caused by individual specimens was expressed as inhibition percentage calculated using the formula: inhibition percentage $=100-\left[100 \times\left(\mathrm{OD}_{450}\right.\right.$ of specimen/OD $\mathrm{OD}_{450}$ of $\mathrm{mAb}$ control)].

\section{Results}

\section{Production and characteristics of mAbs}

MAbs against H5 HA were produced with hybridoma technology as described previously [9]. For mouse immunization, the purified, ectodomain-based H5 HA protein (aa 17-530, $\triangle$ RRRKKR, $6 \times$ His) from a mammalian expression system was used (Additional file 1: Table S1). The sequence of the protein, named rH5mammalian, was derived from the A/Bar-headed Goose/ Qinghai/12/05(H5N1) strain of HPAIV. As shown in our previous papers $[9,12]$, the antigen had characteristics of viral $\mathrm{HA}$. The procedure for obtaining the anti-H5 HA antibodies consisted of spleen/myeloma fusion, screening of the resulting hybridomas and subcloning. In the positive hybridoma selection, the well-characterized recombinant $\mathrm{H} 5 \mathrm{HA}$ proteins were employed in addition to the H5-subtype influenza viruses. This strategy led to the selection of 7 hybridoma cell lines and their respective antibody clones. The affinity-purified antibodies, all of IgG1 isotype, had the same range of immunoreactivity as determined by ELISA. To differentiate antibody clones, immunoreactivity profiling and peptide mapping of antibody fragments were performed [9]. In this way, 6 different anti-H5 HA antibody clones, denoted G-131-22, G-2-14-10, G-5-32-5, G-6-42-42, G-7-24-17, and G-7-27-18, were identified.

According to previously published results [9], the newly established mAbs specifically recognize epitopes in the properly folded HA1 subunit of HAs from multiple strains of the H5-subtype influenza viruses representing both the HP and LP phenotypes. Among these were the H5N3 (1 strain), H5N9 (1 strain), and H5N2 (2 strains) viruses and the $\mathrm{H} 5 \mathrm{~N} 1$ viruses ( 8 strains) belonging to 5 clades. The HA1 subunits of these antigens shared 88 to $99 \%$ of their amino acid sequence identities with the HA1 subunit of the immunogen. Moreover, none of the 6 antibody clones cross-reacted with AIVs of the H1-H4 and $\mathrm{H} 6-\mathrm{H} 16$ subtypes. To complete the analysis of their characteristics, the G-1-31-22, G-2-14-10, G-5-32-5, G-6-42-42, G-7-24-17 and G-7-27-18 mAbs were examined in the HI assay. The test was performed following the protocol outlined in Additional file 2. As presented in Additional file 2: Tables S3 and S4, none of the antibody clones inhibited hemagglutination by $\mathrm{H} 5 \mathrm{~N} 2$ and $\mathrm{H} 5 \mathrm{~N} 3$ LPAIVs. To summarize the results presented in the previous [9] and this paper, we have established a unique panel of 6 different conformation-sensitive antibody clones, each of which is highly and broad-range specific against HAs of the H5-subtype, HP and LP AIVs and lacks HI activity. These properties make the antibodies useful analytical tools, particularly for diagnosing infections with $\mathrm{H} 5 \mathrm{Nx}$ influenza viruses and the DIVA strategy in AIV vaccination campaigns. 


\section{Development of an epitope-blocking (EB) ELISA}

To verify the diagnostic value of the newly generated mAbs, we developed H5 EB-ELISA, the epitope-blocking ELISA for the detection of anti-H5 HA antibodies. The G-7-27-18 mAb was chosen to be a blocking antibody since among the 6 antibody clones, it reacted most uniformly with various $\mathrm{H} 5 \mathrm{HA}$ antigens, as revealed in the immunoreactivity profiles [9]. To avoid steric hindrance by the NA protein, the H5 HA protein was employed as the coating antigen instead of the commonly used inactivated viral antigen. This was the purified, ectodomainbased H5 HA protein (aa 17-530, $\triangle$ RRRKKR, $6 \times$ His) from a baculovirus-expression vector system (Additional file 1: Table S1). The sequence of the protein, referred to as $\mathrm{rH} 5$-BEVS, originated from the $\mathrm{A} / \mathrm{swan} /$ Poland/305135V08/2006(H5N1) strain of HPAIV. Consistent with previously published results $[9,12]$, the antigen was correctly folded and existed in part as a functional oligomer. To detect the complex of rH5-BEVS and G-7-27-18 mAb, anti-mouse $\operatorname{IgG}(\gamma$-chain specific) antibodies labeled with HRP and TMB as the HRP substrate were used. Under the principle EB-ELISA, the assay gives a positive result when antibodies to H5 HA in test sera block binding of $\mathrm{mAb}$ to the target epitope in the coating antigen and thus the color development. Consistently, the ELISA OD values are inversely proportional to the number of epitopespecific antibodies present in the samples.

The H5 EB-ELISA was optimized. The G-7-27-18 $\mathrm{mAb}$ was titrated against $\mathrm{rH5}$-BEVS coated on the well surfaces with varied hydrophilicity (Additional file 3: Fig. S1). In this way, the MediSorp plates were selected to provide the best antigen binding and epitope presentation to the blocking antibody. The plates coated with rH5-BEVS were exploited in testing a panel of samples representing the anti-H5 HA positive and negative sera listed in Table 1. Samples were analyzed at a twofold dilution under different assay conditions. As a result, the blocking and dilution buffers were specified, and the period and temperature of plate incubation at subsequent stages of the assay procedure were established. The optimum concentrations of rH5-BEVS and G-7-27-18 mAb as well as dilution of HRP-labeled, anti-mouse IgG antibodies were determined by titrations. The relevant data are provided in Additional file 3: Figs. S2-S5.

\section{Diagnostic performance of EB-ELISA}

The performance characteristics of the H5 EB-ELISA were evaluated by testing the sera of chickens immunized and not immunized against influenza viruses (Table 1, Additional file 1: Tables S2-S4). The samples were from different-age SPF and non-SPF chickens, representing the two main types of chicken breeds, layer and broiler. They were classified as anti-H5 HA positive or negative based on the results of the HI assay with H5-subtype AIVs. In this study, sera were considered positive when their HI titers were equal to or greater than 1:8. Categories of test samples and their application in the H5 EB-ELISA assessment are provided in Table 1.

The anti-H5 HA-positive samples comprised the reference and experimental antisera (Table 1). They were obtained by immunization of SPF chickens with H5-subtype LPAIVs and commercial chickens with recombinant $\mathrm{H} 5 \mathrm{HA}$ protein. The reference antisera were raised against H5N1, H5N2, H5N3 and H5N9 LPAIVs and had HI titers of 1:256 or 1:512 with homologous virus strains (Additional file 1: Table S2). Experimental antisera originated from previously described semifield trials for vaccine efficacy of the ectodomain-based HA protein produced in Escherichia coli [10]. The sequence of the protein, referred to as $\mathrm{rH} 5-E$. coli, was derived from the H5N1 A/swan/Poland 305-135V08-2006 strain of HPAIV, which is the same strain as rH5-BEVS (Additional file 1: Table S1). As shown previously [12], refolded and purified antigen displayed native HA characteristics. Commercial layer chickens were vaccinated twice with different doses of alum-adjuvanted rH5-E. coli [10]. For analyses, postvaccination sera with $\mathrm{HI}$ titers from 1:8 to 1:512 against heterologous H5N2 LPAIV were selected (Additional file 1: Table S4).

The panel of samples negative against H5 HA (Table 1) included the normal chicken serum, sera of SPF layer chickens and sera from commercial layers and broilers, which served as the nonvaccinated controls in the immunization studies with rH5-E. coli. Another category of anti-H5 HA negative samples was the reference antisera raised in the SPF chickens against the non-H5 subtype LPAIVs (Additional file 1: Table S3). These samples were positive against $\mathrm{HAs}$ of the $\mathrm{H} 1-\mathrm{H} 4$ and $\mathrm{H} 6-\mathrm{H} 16$ subtypes, as confirmed by the results of the HI assay with the respective virus strains.

The chicken sera, for a total of 358 samples, were tested by H5 EB-ELISA to represent different sample categories, listed in Table 1, which were analyzed in parallel. Each assay included the mAb control, anti-H5N2 and anti-H5N3 LPAIV antisera as the weak and strong positive controls, respectively, and the normal chicken serum as a negative control (Table 1). The ability of individual specimens to block the binding of the G-7-27-18 mAb to rH5-BEVS was expressed in terms of inhibition percentage. The threshold for positivity and negativity in the H5 EB-ELISA, a cutoff value of $38.5 \%$, was obtained by adding two standard deviation (SD) values to the arithmetic mean of the inhibition percentages set for 209 samples of various-origin sera that were negative against $\mathrm{H} 5$ HA. Data from analyses of the anti-H5 HA negative and positive sera (232 and 126 samples, respectively) were 
summarized by calculation of arithmetic means \pm SD of the inhibition percentages determined for the independent assays of individual samples or samples in the serum groups. The first approach was applied to the normal chicken serum and anti-LPAIV reference antisera, while the second was applied to the anti-H5 HA negative sera of various origins and groups of anti-H5 HA positive experimental antisera with different $\mathrm{HI}$ titers. As shown in Fig. 1, the mean inhibition percentages for the antiH5 HA negative sera from the nonimmunized chickens and chickens immunized with AIVs of the $\mathrm{H} 1-\mathrm{H} 4$ and H6-H16 subtypes were below the cutoff value of $38.5 \%$. In contrast, the mean inhibition percentages for the anti-H5 HA positive reference and experimental antisera were above this value. Thus, the H5 EB-ELISA correctly discriminated between the anti-H5 HA negative sera, including those against the non-H5 subtype AIVs, and sera positive for antibodies against $\mathrm{H} 5$ HAs. The H5 subtype-specific antibodies were detected in the reference and experimental antisera despite the HA antigens used to obtain them having been from highly divergent $\mathrm{H} 5$-subtype influenza viruses. The HA1 subunits of HAs of the H5N3, H5N1, H5N9 and H5N2 LPAIVs and rH5E. coli shared 90 to $100 \%$ of their amino acid sequence identities with the HA1 subunit of rH5-BEVS, which contained an epitope for detected serum antibodies and G-7-27-18 mAb (Additional file 1: Table S7).

The H5 EB-ELISA was characterized using the key criteria of assay validation, such as specificity, sensitivity and repeatability of the assay and HI test as the gold standard. Analytical and diagnostic specificities (Asp and Dsp, respectively) were evaluated by calculating the percentage of samples negative in this test among the sera lacking $\mathrm{HI}$ activity against $\mathrm{H} 5$-subtype AIVs (Table 1). Data obtained for sera of chickens immunized with LPAIVs of the $\mathrm{H} 1-\mathrm{H} 4$ and $\mathrm{H} 6-\mathrm{H} 16$ subtypes allowed us to establish the Asp value of $100 \%$ (Table 2). Based on the test results for sera from the nonimmunized chickens, the Dsp value of $97.6 \%$ was determined (Table 2).

Diagnostic sensitivity (Dse) of the H5 EB-ELISA was evaluated by calculating the percentage of samples positive in the test among the antisera with $\mathrm{HI}$ titers against H5-subtype AIVs of 1:8 or greater (Table 1). In this way, Dse values of $98.0 \%$ and $99.1 \%$ were established from the assay results for the reference and experimental antisera, respectively (Table 2). Of note, the true positive sera included all of the samples with HI titers of 1:8 (Table 2), which would be interpreted as being negative according to recommendations of OIE [3]. In this context, the H5 EB-ELISA can be considered more sensitive than the HI assay in detecting $\mathrm{H} 5$ subtype-specific antibodies. The sensitivity of the H5 EB-ELISA was also assessed by a comparison to those of the commercial ELISA test, ID
Screen Influenza H5 Antibody Competition-FluAC H5. The test is a diagnostic kit designed to specifically detect antibodies directed against the $\mathrm{H} 5$ antigen of influenza $\mathrm{A}$ viruses in bird sera. Analyses of the anti-H5 HA antisera using the FluAC $\mathrm{H} 5$ test were performed and interpreted as described in Additional file 4. According to the data in Additional file 4: Tables S1 and S2, the reference and experimental antisera were determined in the FluAC H5 test with $100 \%$ and $80.9 \%$ sensitivities, respectively. Thus, the developed H5 EB-ELISA was less sensitive than the commercial test in detecting the anti-H5 HA antibodies raised in chickens with $\mathrm{H} 5$-subtype influenza viruses. However, it was substantially more sensitive in testing the antisera obtained using the vaccine H5 HA protein for chicken immunization.

The high specificity and sensitivity of the H5 EB-ELISA, as indicated by values of Asp, Dsp and Dse (Table 2), were accompanied by a satisfactory repeatability of the assay. Values of relative standard deviation (RSD) from the independent testing of the mAb control, negative controls and positive controls were between 7.1 and $10.0 \%$ (Table 2). In summary, the developed H5 EB-ELISA fulfills criteria for effective detection of antibodies against HAs of H5-subtype influenza viruses.

\section{Discussion}

The H5-subtype HPAIVs, such as the H5N1, H5N2, H5N6, and H5N8 viruses, are of both veterinary and public health concern worldwide. Infection with these viruses leads to multiorgan disease and death in domestic birds $[5,6]$. After bird-to-human transmission, the $\mathrm{H} 5 \mathrm{~N} 1$ viruses cause severe disease with a frequently fatal outcomes, and their pandemic potential is commonly recognized [7]. For these reasons, H5-subtype HPAIVs and LPAIVs with a propensity to mutate into HP viruses are under epidemiologic surveillance as NAIVs, which is accomplished using a variety of methods recommended by OIE [3]. Our initial work in the area of H5Nx AIV diagnostics provided 6 different antibody clones against the HA1 subunit of HA [9]. Each of these mAbs showed broad strain specificity against AIVs of the H5 subtype and did not cross-react with non-H5 subtype virus strains. The study presented here resulted in a prototype H5 EB-ELISA for detecting anti-H5 HA antibodies in chicken sera, which was based on the G-7-27-18 mAb selected from the newly generated antibody clones.

Consistent with the characteristics of the blocking mAb [9], all of the analyzed antisera against HAs of the $\mathrm{H} 1-\mathrm{H} 4$ and $\mathrm{H} 6-\mathrm{H} 16$ subtypes tested negative in the $\mathrm{H} 5$ EB-ELISA (Fig. 1, Table 2), which proves that the assay is truly $\mathrm{H} 5$-subtype specific. In addition, the anti-H5 HA negative, various-origin sera were determined with high specificity (Fig. 1, Table 2). To further refine the 


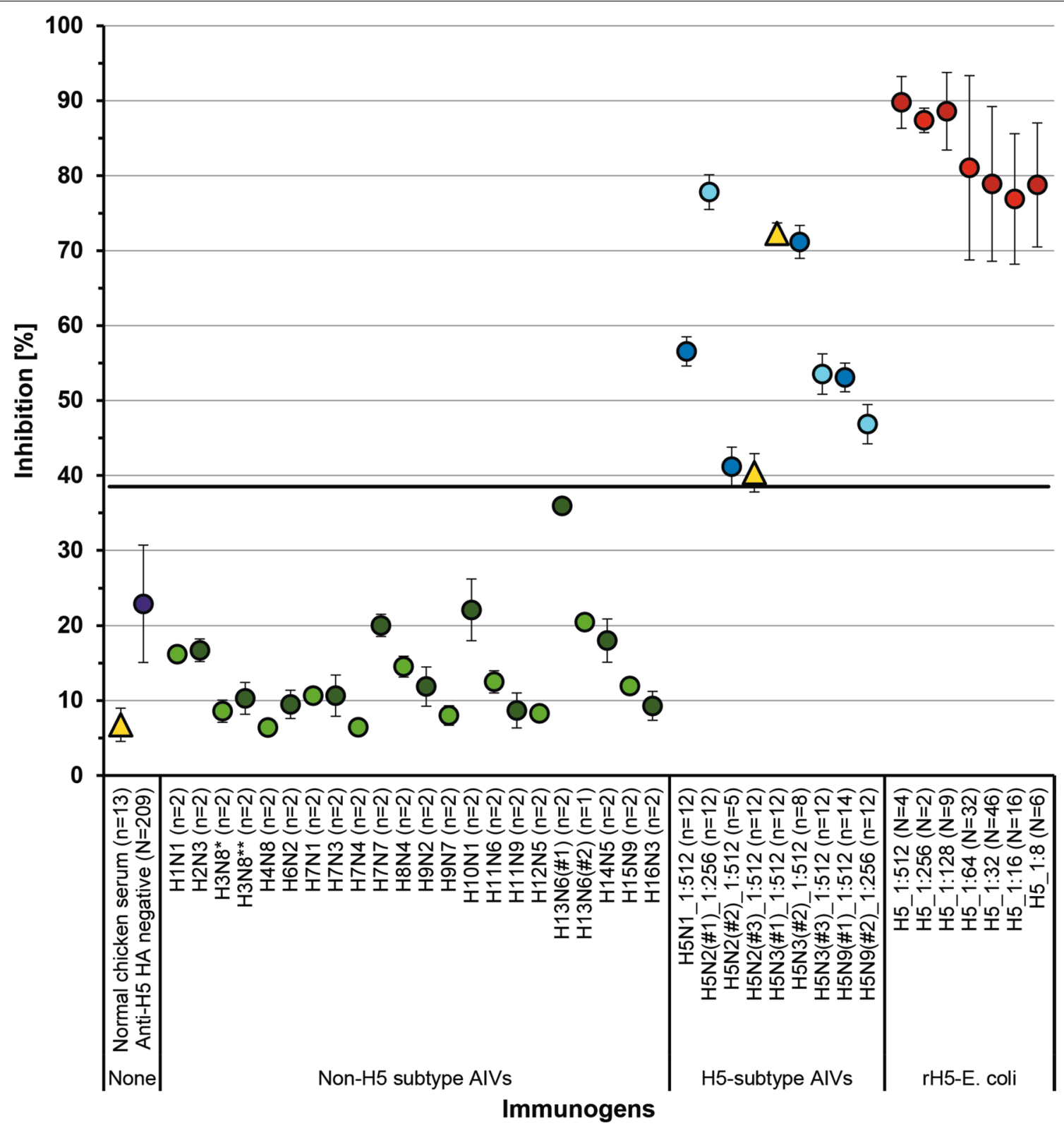

Fig. 1 Discrimination between the anti-H5 HA positive and negative sera in the H5 EB-ELISA. Serum samples of the nonimmunized chickens and chickens immunized with LPAIVs and recombinant HA protein from the H5N1 HPAIV (rH5-E. coli) to obtain the reference and experimental antisera, respectively, were analyzed in the EB-ELISA as described in the Methods section. Data on the analyzed samples are provided in Table 1 and Additional file 1: Tables S2-S4. Annotations for the horizontal axes refer to serum category and subcategory. The reference antisera were denoted according to the HA and NA subtypes of AIV used for chicken inoculation. Denotations of antisera against H5-subtype AlVs were completed with HI titers determined using the homologous virus strains and provided in the certificates. The ${ }^{*}$ and ${ }^{* *}$ symbols were applied to discriminate between different virus strains of the same HA and NA subtype, while the \# symbol followed by the numbers $(1,2$ or 3$)$ discriminate among the antiserum batches. Experimental antisera were denoted according to the vaccine HA subtype and HI titers against heterologous H5N2 LPAIV adapted from our previous paper [10]. Annotations of the vertical axes refer to the test results, expressed as the inhibition percentages. The cutoff value of the test was calculated from the inhibition percentages set for anti-H5 HA negative sera of the nonimmunized chickens (arithmetic mean $+2 \times S D$ ) and shown as the horizontal line. The results for individual serum subcategories are presented as the arithmetic means \pm SD of the inhibition percentages calculated for the indicated number of independent sample assays ( $n$ ) or samples tested $(\mathrm{N})$. Triangle and circle symbols represent the results for the control and the remaining sera, respectively. Samples showing inhibition above the cutoff value of $38.5 \%$ were considered positive against HA of H5-subtype influenza viruses 
Table 2 Preliminary validation of the H5 EB-ELISA

\begin{tabular}{|c|c|c|c|c|c|}
\hline Validation criteria and the samples used & Samples [N] & Assays [n] & Results & & \\
\hline \multirow[t]{2}{*}{ Analytical specificity (Asp) } & & & True negative & False positive & Asp (\%) \\
\hline & & & $\mathrm{TN}$ & $\mathrm{FP}$ & $\mathrm{TN} /(\mathrm{TN}+\mathrm{FP})$ \\
\hline Reference antisera against non-H5 subtype LPAIVs & 22 & 43 & 43 & 0 & 100 \\
\hline \multirow[t]{2}{*}{ Diagnostic specificity (Dsp) } & & & True negative & False positive & Dsp [\%] \\
\hline & & & $\mathrm{TN}$ & $\mathrm{FP}$ & $\mathrm{TN} /(\mathrm{TN}+\mathrm{FP})$ \\
\hline Various-origin sera negative against $\mathrm{H} 5 \mathrm{HA}$ & 209 & 209 & 204 & $5^{a}$ & 97.6 \\
\hline \multirow[t]{2}{*}{ Diagnostic sensitivity (Dse) 1} & & & True positive & False negative & Dse $1(\%)$ \\
\hline & & & $\mathrm{TP}$ & FN & $\mathrm{TP} /(\mathrm{TP}+\mathrm{FN})$ \\
\hline Reference antisera against H5-subtype LPAIVs & 9 & 99 & 97 & $2^{b}$ & 98.0 \\
\hline \multirow[t]{2}{*}{ Diagnostic sensitivity (Dse) 2} & & & True positive & False negative & Dse $2(\%)$ \\
\hline & & & $\mathrm{TP}$ & FN & $\mathrm{TP} /(\mathrm{TP}+\mathrm{FN})$ \\
\hline Experimental antisera against HA from H5N1 HPAIV & 115 & 115 & 114 & $1^{c}$ & 99.1 \\
\hline Repeatability of assays & & & Mean $\left[\mathrm{OD}_{450}\right]$ & $S^{d}$ & $\operatorname{RSD}^{\mathrm{e}}(\%)$ \\
\hline G-7-27-18 mAb control & 1 & 13 & 1.566 & 0.111 & 7.1 \\
\hline Normal chicken serum (negative control) & 1 & 13 & 1.460 & 0.114 & 7.8 \\
\hline Anti-H5N2 LPAIV antiserum (weak positive control) & 1 & 12 & 0.944 & 0.083 & 8.8 \\
\hline Anti-H5N3 LPAIV antiserum (strong positive control) & 1 & 12 & 0.439 & 0.044 & 10.0 \\
\hline
\end{tabular}

Serum samples (Table 1) were classified as anti-H5 HA positive or negative based on the $\mathrm{HI}$ assay results. $\mathrm{HI}$ titers for the reference antisera were provided in the product certificates. Normal chicken serum and sera from commercial chickens immunized and nonimmunized with rH5-E. coli were analyzed in the HI assay according to the protocol included in the Methods section. Data for all experimental antisera and 96 out of 210 sera negative against $\mathrm{H} 5 \mathrm{HA}$ were adapted from our previous paper [10]. HI titers for the reference and experimental antisera against H5-subtype AIVs are provided in Table 1 and Additional file 1: Tables S2 and S4. In this study, serum HI titers equal to or greater than 1:8 were considered positive. The H5 EB-ELISA was performed, and inhibition percentages were calculated as described in the Methods section. Samples showing inhibition above the cutoff value of $38.5 \%$ were considered positive against HA of H5-subtype influenza viruses in the EB-ELISA. Analytical and diagnostic specificities were calculated by counting the samples determined in the EB-ELISA as true negatives among the anti-H5 $\mathrm{HA}$ negative sera from chickens immunized with LPAIVs of the $\mathrm{H} 1-\mathrm{H} 4$ and $\mathrm{H} 6-\mathrm{H} 16$ subtypes and the nonimmunized chickens, respectively. Diagnostic sensitivities 1 and 2 were calculated by counting the samples determined in the EB-ELISA as true positives among the anti-H5 HA positive reference and experimental antisera, respectively. The repeatability of the EB-ELISA was evaluated by performing the indicated number of assays for the listed control samples

a The samples yielding from 39.7 to $43.0 \%$ inhibition

${ }^{b}$ Two out of twelve assays of the anti-H5N2 LPAIV antiserum, batch \#3, with an HI titer of 1:512

'The sample with an $\mathrm{HI}$ titer of 1:64

d Standard deviation

e Relative standard deviation

H5 EB-ELISA, a larger number of anti-H5 HA negative specimens need to be analyzed to correct the cutoff value and/or indicate the doubtful threshold. Alternatively, the cutoff value could be optimized by using the receiver operating characteristic (ROC) analysis on the larger set of data.

The H5 EB-ELISA enabled not only specific but also sensitive detection of $\mathrm{H} 5$ subtype-specific antibodies, especially when applied to examine sera from chickens immunized using the H5 HA protein (Fig. 1, Table 2, Additional file 4: Table S2). Thus, the developed assay is particularly suitable for the differentiation of infected chickens from chickens vaccinated with anti-H5Nx virus vaccines based on recombinant H5 HA proteins. Most recently, the Volvac ${ }^{\circledR}$ B.E.S. T AI $+\mathrm{ND}$ vaccine containing the $\mathrm{H} 5 \mathrm{HA}$ protein of baculovirus-expression system origin has been positively evaluated by efficacy trials in commercial chickens [13]. In general, recombinant DNA technology has been widely explored to obtain influenza virus HA protein, as exemplified by rH5-E. coli $[10,12]$. Thus, the contribution of such vaccines in antiAIV vaccination programs can be expected to increase, similar to the utility of the H5 EB-ELISA with its current characteristics.

Our results confirmed that the H5 EB-ELISA performed well in screening the SPF chickens immunized with H5-subtype LPAIVs. Nevertheless, the sensitivity of detecting the anti-H5 HA antibodies in the reference antisera was lower than in the experimental antisera (Fig. 1, Table 2) and was decreased in comparison to those achieved with the FluAC H5 test (Additional file 4: Table S1). Therefore, it would be advisable to further optimize the H5 EB-ELISA to increase the sensitivity of detecting $\mathrm{H} 5$ subtype-specific serum antibodies induced with $\mathrm{H} 5 \mathrm{Nx}$ influenza viruses. Thus, the optimized assay would be more effective as a DIVA test in vaccination programs utilizing predominantly oil-emulsified, inactivated whole AIV vaccines [4]. It would probably work 
better when used for the diagnosis of infection with H5-subtype influenza viruses.

Thus far, only a few experimental bELISA and cELISA tests designated to detect anti-H5 HA antibodies have been developed and evaluated [14-20]. These assays have employed mAbs predominantly to the highly variable HA1 subunit of HA [14-16, 20], and as an exception against the relatively well-conserved HA2 subunit of the antigen [17]. The tests reported by Chen et al. [14] and Yang et al. [15] did not show cross-reactions with non-H5 subtype AIVs; however, their confirmed H5-subtype specificities were restricted to a single $\mathrm{H} 5 \mathrm{~N} 2$ virus strain [14] or three strains representing the H5N1 and H5N2 AIVs [15]. Prabakaran et al. [16] developed bELISA based on the mAb to the linear epitope in the HA1 subunit with $100 \%$ and $96.9 \%$ conservation rates among the H5N1 virus isolates from humans and avian sources, respectively, while $54.3 \%$ conservation rates were observed in the H5-subtype viruses with an NA subtype other than N1. Consequently, the assay provided the highly sensitive detection of antibodies against HAs of various-origin $\mathrm{H} 5 \mathrm{~N} 1$ viruses in chicken and human sera, but predictably, it would not detect the anti-HA antibodies in approximately $50 \%$ of antisera raised against $\mathrm{H} 5 \mathrm{~N} 2-\mathrm{N} 9$ viruses. In contrast, Postel et al. [17] set up the broadly reacting cELISA for anti-H5 HA antibody detection using mAb, which recognized a linear epitope conserved within the H5-subtype influenza viruses and located in the HA2 subunit. The assay demonstrated good diagnostic specificity and sensitivity in testing sera from different avian species but also substantial cross-reactivity with $\mathrm{H} 2$ subtype-specific sera and, to a lesser extent, with sera specific for $\mathrm{H} 1$ and $\mathrm{H} 6$ subtypes. Thus, this H5 cELISA did not allow for a clear distinction between antisera against HAs of the $\mathrm{H} 5$ and $\mathrm{H} 2, \mathrm{H} 1$ or $\mathrm{H} 6$ subtypes. In the H5-subtype cELISA described by Dlugolenski et al. [18], no intersubtype cross-reactions were found, but the accuracy of the test was low and varied between the avian species tested. The diagnostic specificity and sensitivity of this assay calculated across all chicken, duck and turkey sera were $32 \%$ and $85 \%$, respectively, and those for chicken sera were $63 \%$ and $66 \%$, respectively. The high specific and sensitive detection of antibodies to H5 HA in chicken sera was achieved in the bELISA designed by Jensen et al. [19]. However, the high accuracy of the test was achieved only after two subsequent ELISAs were performed using the H5N7 and H5N2 inactivated viruses as the coating antigens to circumvent interference with the NA protein. In addition, the H5-subtype specificity of this bELISA was not adequately validated, as only five subtypes other than $\mathrm{H} 5$ were considered in the cross-reactivity testing.

The most promising studies presenting mAbs against $\mathrm{H} 5 \mathrm{HA}$ and the application of one of them, the 5D8 mAb, in the development of H5 cELISA were described by Moreno et al. [20]. The assay clearly differentiated homologous and heterologous positive sera and performed very well in terms of diagnostic specificity and sensitivity for different avian species. Such performance characteristics of the assay were due to the wide intra-H5-subtype reactivity of the 5D8 mAb. It was shown that the competitor antibody recognizes a conformational epitope in the receptor-binding domain of the HA1 subunit and inhibits hemagglutination by $\mathrm{H} 5$-subtype AIVs. This implies that the cELISA will not detect antibodies to influenza viruses mutated under selection pressure of $\mathrm{HI}$ antibodies targeting the binding epitope of the 5D8 mAb. Owing to usage of the G-7-27-18 mAb with no HI activity (Additional file 2: Tables S3 and S4), detectability of the H5-subtypespecific antibodies in the EB-ELISA presented here is not affected by mutations induced with $\mathrm{HI}$ antibodies. In this respect, the assay developed by us is advantageous over the cELISA reported by Moreno et al. [20].

The blocking antibody in the present H5 EB-ELISA combines the inability to inhibit hemagglutination with high and broad-range specificity against H5 HAs [9], indicating conservation of its target epitope within HAs of the H5-subtype influenza viruses. Thus, the assay can be expected to diagnose infections with the currently circulating and novel $\mathrm{H} 5 \mathrm{Nx}$ viral strains. As such, the H5 EB-ELISA meets the demand for diagnostic tools to accurately identify the HA-subtype specificity of antibodies to AIV, which is reported despite the availability of commercial kits [4]. The examples are the FluAC H5 test (IDVet, France) and H5-HA antibody ELISA kit (Dialab, Germany), which are designed to detect the anti-H5 HA antibodies in bird and human sera, respectively. The diagnostic performance of the FluAC H5 test has been evaluated in the domestic poultry population of Vietnam, partially vaccinated with reassortant $\mathrm{H} 5 \mathrm{~N} 1$ LP virus vaccine [21], ducks experimentally infected with LP and HP H5-subtype AIVs or immunized with H5 HAencoding DNA vaccine [22], waterfowl experimentally infected with LP and HP H5N1 AIVs [23], mute swans [24], and zoo birds vaccinated with inactivated H5N9 AI vaccine [25]. In some of these studies, the assay showed low degree of cross-reactivity with antisera to the nonH5 subtype AIVs [21], a specificity value of only $89.4 \%$ [22] and variable sensitivity depending on the tested viral strain $[17,23]$. In particular, low rates of detecting antiH5 HA antibodies, $14 \%$ and $22 \%$, were noted for antisera against the A/Chicken/West Java/SMI-PAT/2006 H5N1 HPAIV [23] and Egyptian HPAIV H5N1 antigenic drift variant [17], respectively. To improve the performance of the FluAC H5 test, modifications to the manufacturer's protocols $[23,24]$ or revalidation of the cutoff value [21] are suggested. Evaluation of the H5-HA antibody ELISA 
kit showed that the assay detects only high levels of antiH5 HA antibodies and may produce false positive results for antisera towards seasonal $\mathrm{H} 3 \mathrm{~N} 2$ and $\mathrm{H} 1 \mathrm{~N} 1$ influenza viruses [26].

The disadvantages of the referenced experimental and commercial ELISAs justify our efforts to provide a novel screening test for subtype-specific serodiagnosis and surveillance. The accuracy of the current H5 EB-ELISA is sufficiently high to consider its further optimization and validation in accordance with the OIE guidelines [27]. Future analyses should include sera from chickens infected with $\mathrm{H} 5 \mathrm{Nx}$ viruses. Depending on the scope of validation work, the test could be used for serological analyses in chickens and other poultry species, such as geese, ducks or turkeys, as well as in wild birds. The present H5 EB-ELISA also provides a basis for developing an assay designed to diagnose infection with $\mathrm{H} 5 \mathrm{Nx}$ influenza viruses in humans.

\section{Conclusions}

The H5 EB-ELISA developed in this study performed well in terms of Asp, Dsp and Dse when applied to screen chicken sera for the presence of $\mathrm{H} 5$ subtype-specific antibodies. Thus, the assay warrants further optimization and validation work using a larger set of sera and ROC analysis to select the optimal cutoff, Dsp and Dse values. Furthermore, validation studies could be expanded with serological analyses in a variety of domestic and wild birds to provide a multispecies assay. In large-scale serosurveillance examinations or AIV vaccination campaigns, an optimized and fully validated H5 EB-ELISA would be a useful alternative to the HI test. The current H5 EBELISA is also a valuable starting point to develop a diagnostic test for humans.

\footnotetext{
Abbreviations

IV: Influenza virus; RNA: Ribonucleic acid; NP: Nucleoprotein; M1: Matrix protein; M2: Membrane protein; NS1: Nonstructural protein; NEP: Nuclear export protein; HA: Hemagglutinin; NA: Neuraminidase; AIV: Avian influenza virus; LP: Low pathogenic; HP: Highly pathogenic; OIE: World Organization for Animal Health; NAIV: Notifiable avian influenza virus; rRT-PCR: Real-time reverse transcriptase polymerase chain reaction; AGID: Agar gel immunodiffusion; ELISA: Enzyme-linked immunosorbent assay; HI: Hemagglutination inhibition; NI: Neuraminidase inhibition; CELISA: Competitive enzyme-linked immunosorbent assay; bELISA: Blocking enzyme-linked immunosorbent assay; DIVA: Differentiation infected from vaccinated animals; MAb: Monoclonal antibody; EB: Epitope-blocking; IgG: Immunoglobulin G class; Fab: Antigen-binding fragment; Fc: Crystallizable fragment; MALDI-TOF/TOF: Matrix-Assisted Laser Desorption lonization Time of Flight; SPF: Specific pathogen-free; BEVS: Baculovirus expression vector system; OD: Optical density; SD: Standard deviation; Asp: Analytical specificity; Dsp: Diagnostic specificity; Dse: Diagnostic sensitivity; RSD: Relative standard deviation; ROC: Receiver operating characteristic.
}

\section{Supplementary Information}

The online version contains supplementary material available at https://doi. org/10.1186/s12985-021-01564-6.

Additional file 1. Supplementary data on antigens and sera. Table S1. Recombinant H5 HA proteins (ITC, OET Ltd., IBA). Table S2. Reference antisera against LPAIVs of the $\mathrm{H} 5$ subtype ( $\mathrm{x}-\mathrm{OV}$ O Ltd.). Table S3. Reference antisera against LPAIVs of the non-H5 subtypes ( $\mathrm{x}$-OvO Ltd.). Table S4. Experimental antisera against HA from H5N1 HPAIV (IBA). Table S5.

Antigens and antisera ( $\mathrm{x}$-OvO Ltd.) used in the HI tests performed at IBA. Table S6. Homology of H5 HA antigens against rH5-mammalian, an immunogen used in mAb production. Table S7. Homology of H5 HA antigens against rH5-BEVS, the coating antigen in the EB-ELISA.

Additional file 2. Verification of mAb activity in the hemagglutination inhibition assay. Table S1. Antigens and antisera used in testing the mAbs for $\mathrm{HI}$ activity. Table S2. Commercial mAbs against H5 HA used as controls in the HI assays. Table S3. Results of the HI assay with H5N2 LPAIV. Table S4. Results of the HI assay with H5N3 LPAIV.

Additional file 3. Development and optimization of H5 EB-ELISA. Fig. S1. The ELISA titration curves of G-7-27-18 mAb against rH5-BEVS coated on the well surfaces with varied hydrophilicity. Titration curves were denoted according to the plate type. Fig. S2. The ELISA titration curves of G-7-27$18 \mathrm{mAb}$ against $\mathrm{rH} 5$-BEVS under preliminary assay conditions. $\mathrm{rH} 5$-BEVS was coated at (A) $1.0 \mu \mathrm{g} / \mathrm{mL}$ or (B) $0.5 \mu \mathrm{g} / \mathrm{mL}$ on MediSorp plates. Titration curves were denoted according to the coating concentration of $\mathrm{rH} 5$-BEVS in $\mu \mathrm{g}$ per $\mathrm{mL}(1 \mu \mathrm{g}$ or $0.5 \mu \mathrm{g})$ and then the time of plate incubation with G-7-27-18 mAb (60 min or $30 \mathrm{~min}$ ), anti-mouse antibodies (60 min or $30 \mathrm{~min})$ at the indicated dilution $(1: 1,000)$ and TMB $(15 \mathrm{~min}$ or $10 \mathrm{~min})$. Fig. S3. The ELISA titration curves of G-7-27-18 mAb against rH5-BEVS under assay conditions optimized in step 1. Titration curves were denoted according to the coating concentration of rH5-BEVS in $\mu \mathrm{g}$ per $\mathrm{mL}(0.5 \mu \mathrm{g})$ and then the time of plate incubation with G-7-27-18 mAb (60 min or $30 \mathrm{~min}$ ), anti-mouse antibodies (60 $\mathrm{min})$ at the indicated dilutions (1:1,000, $1: 1,500,1: 2,000$ or 1:2,500) and TMB (15 min). Fig. S4. The ELISA titration curves of G-7-27-18 mAb against rH5-BEVS under assay conditions optimized in step 2. Titration curves were denoted according to the coating concentration of $\mathrm{rH} 5$-BEVS in $\mu \mathrm{g}$ per $\mathrm{mL}(0.5 \mu \mathrm{g})$ and then the time of plate incubation with G-7-27-18 mAb (60 min or $30 \mathrm{~min}$ ), anti-mouse antibodies (60 $\mathrm{min}$ ) at the indicated dilutions $(1: 1,500,1: 2,000,1: 3,000$ or 1:4,000) and TMB (15 min). Fig. S5. The ELISA titration curves of G-7-27$18 \mathrm{mAb}$ against $\mathrm{rH} 5$-BEVS under assay conditions optimized in step 3. Titration curves were denoted according to the coating concentration of $\mathrm{rH} 5$-BEVS in $\mu \mathrm{g}$ per $\mathrm{mL}(0.5 \mu \mathrm{g})$ and then the time of plate incubation with G-7-27-18 $\mathrm{mAb}(60 \mathrm{~min})$, anti-mouse antibodies (60 $\mathrm{min}$ ) at the indicated dilutions (1:2,500, 1:3,000, 1:3,500 or 1:4,000) and TMB (15 min).

Additional file 4. Sensitivity of H5 EB-ELISA relative to the commercial FluAC $\mathrm{H} 5$ test. Table S1. Detection of H5 subtype-specific antibodies in the reference antisera. Table $\mathbf{S 2}$. Detection of $\mathrm{H} 5$ subtype-specific antibodies in the experimental antisera.

\section{Acknowledgements}

Not applicable.

\section{Authors' contributions}

VS conceived and designed the experiments, analyzed the data, performed the statistical analyses, prepared the tables and figures and wrote the manuscript. KF-J assisted in the hybridoma screening and performed the experiments. AP produced monoclonal antibodies. VC-A characterized and purified antibodies, performed the hemagglutination inhibition assays and assisted with data visualization. All authors read and approved the final manuscript. 


\section{Funding}

This work was supported by the Innovative Economy Operational Program, Grant No. WND-POIG.01.01.02-00-007/08-00, as a part of the project'Center of medicinal product biotechnology. Package of innovative biopharmaceuticals for human and animal therapy and prophylactics' and Grant No. PBS2/ A7/14/2014 (ID: 210068): Influenza vaccine-innovative obtaining of subunit antigens.'The funders had no role in the design of the study and collection, analysis, and interpretation of data or in writing the manuscript.

\section{Availability of data and materials}

The results described here are contained in the Patent U.S. 10,696,737 (2020-06-20) and Patent Applications P.418671 (2016-09-12) and PCT/ PL2017/000084 (2017-09-11): Monoclonal antibodies against hemagglutinin of H5-subtype influenza viruses and uses thereof, hybridomas producing the said antibodies, compositions and diagnostic kits. The datasets supporting the conclusions of this article are included within the article and its additional files. The newly established G-7-27-18 hybridoma cell line producing G-7-27$18 \mathrm{mAb}$ used in the presented EB-ELISA was given Accession Number DSM ACC3297 by the International Depositary Authority and is held by the Leibniz Institute DSMZ-German Collection of Microorganisms and Cell Cultures (Braunschweig, Germany).

\section{Declarations}

\section{Ethics approval and consent to participate}

All work with mice was approved by the Second Local Ethical Committee for Animal Experiments at the Medical University of Warsaw (Poland), Permit Number 38/2008.

\section{Consent for publication}

Not applicable.

\section{Competing interests}

All the authors (VS, KF-J, AP \& VC-A) are inventors of the U.S. Patent 10,696,737 (2020-06-20) and have filed Patent Applications P.418671 (2016-09-12) and PCT/PL2017/000084 (2017-09-11). The patent and patent applications contain the findings reported in this paper. The authors declare that they have no competing interests.

Received: 13 October 2020 Accepted: 22 April 2021 Published online: 30 April 2021

\section{References}

1. International Committee on Taxonomy of Viruses. Virus Taxonomy: 2019 Release. http://www.ictvonline.org.

2. Krammer F, Smith GJD, Fouchier RAM, Peiris M, Kedzierska K, Doherty PC, Palese P, Shaw ML, Treanor J, Webster RG, García-Sastre A. Influenza. Nat Rev Dis Primers. 2018;4:3. https://doi.org/10.1038/s41572-018-0002-y.

3. World Organization for Animal Health. Manual of Diagnostic Tests and Vaccines for Terrestrial Animals 2018. Chapter 3.3.4. Avian influenza (infection with avian influenza viruses). https://www.oie.int/fileadmin/Home/ eng/Health_standards/tahm/3.03.04_Al.pdf.

4. Swayne DE, Spackman E. Current status and future needs in diagnostics and vaccines for high pathogenicity avian influenza. Dev Biol (Basel). 2013;135:79-94. https://doi.org/10.1159/000325276.

5. Verhagen $\mathrm{JH}$, Herfst S, Fouchier RA. Infectious disease. How a virus travels the world. Science. 2015;347:616-7. https://doi.org/10.1126/science. aaa6724.

6. de Vries E, Guo H, Dai M, Rottier PJ, van Kuppeveld FJ, de Haan CA. Rapid emergence of highly pathogenic avian influenza subtypes from a subtype H5N1 hemagglutinin variant. Emerg Infect Dis. 2015;21:842-6. https://doi.org/10.3201/eid2105.141927.

7. World Health Organization. Cumulative number of confirmed human cases for avian influenza $\mathrm{A}(\mathrm{H} 5 \mathrm{~N} 1)$ reported to WHO, 2003-2020. https:// www.who.int/influenza/human_animal_interface/2020_10_07_table H5N1.pdf?ua=1. Accessed 10 July 2020.

8. Comin A, Toft N, Stegeman A, Klinkenberg D, Marangon S. Serological diagnosis of avian influenza in poultry: is the haemagglutination inhibition test really the "gold standard"? Influenza Other Respir Viruses. 2013;7:257-64. https://doi.org/10.1111/j.1750-2659.2012.00391.x.

9. Sączyńska V, Bierczyńska-Krzysik A, Cecuda-Adamczewska V, Baran P, Porębska A, Florys K, Zieliński M, Płucienniczak G. Production of highly and broad-range specific monoclonal antibodies against hemagglutinin of H5-subtype avian influenza viruses and their differentiation by mass spectrometry. Virol J. 2018;15:13. https://doi.org/10.1186/ s12985-017-0886-2.

10. Sączyńska V, Romanik-Chruścielewska A, Florys K, Cecuda-Adamczewska V, Łukasiewicz N, Sokołowska I, Kęsik-Brodacka M, Płucienniczak G. Prime-boost vaccination with a novel hemagglutinin protein produced in bacteria induces neutralizing antibody responses against H5-subtype influenza viruses in commercial chickens. Front Immunol. 2019;10:2006. https://doi.org/10.3389/fimmu.2019.02006.

11. World Organization for Animal Health. Manual of Diagnostic Tests and Vaccines for Terrestrial Animals 2012. Chapter 2.3.4. Avian influenza. http://www.oie.int/doc/ged/D12008.PDF.

12. Sączyńska V, Romanik A, Florys K, Cecuda-Adamczewska V, KęsikBrodacka M, Śmietanka K, Olszewska M, Domańska-Blicharz K, Minta Z, Szewczyk B, Płucienniczak G, Płucienniczak A. A novel hemagglutinin protein produced in bacteria protects chickens against H5N1 highly pathogenic avian influenza viruses by inducing H5 subtype-specific neutralizing antibodies. PLoS ONE. 2017;12:e0172008. https://doi.org/10. 1371/journal.pone.0172008.

13. Hamad M, Amen O, Mahmoud M, Hassanin O, Saif-Edin M. Effectiveness of different avian influenza $(\mathrm{H} 5)$ vaccination regimens in layer chickens on the humoral immune response and interferon-alpha signalling immune marker. Vet Res Commun. 2018;42:145-52. https://doi.org/10. 1007/s11259-018-9717-1.

14. Chen YC, Chen $\mathrm{CH}$, Wang $\mathrm{CH}$. $\mathrm{H} 5$ antibody detection by blocking enzyme-linked immunosorbent assay using a monoclonal antibody. Avian Dis. 2008;52:124-9. https://doi.org/10.1637/8076-071807-Reg.

15. Yang M, Clavijo A, Graham J, Salo T, Hole K, Berhane Y. Production and diagnostic application of monoclonal antibodies against influenza virus H5. J Virol Methods. 2009;162:194-202. https://doi.org/10.1016/j.jviromet. 2009.08.006.

16. Prabakaran M, Ho HT, Prabhu N, Velumani S, Szyporta M, He F, Chan KP, Chen LM, Matsuoka Y, Donis RO, Kwang J. Development of epitopeblocking ELISA for universal detection of antibodies to human $\mathrm{H} 5 \mathrm{~N} 1$ influenza viruses. PLoS ONE. 2009;4:e4566. https://doi.org/10.1371/journ al.pone.0004566.

17. Postel A, Ziller M, Rudolf M, Letzel T, Ehricht R, Pourquier P, Dauber M, Grund C, Beer M, Harder TC. Broad spectrum reactivity versus subtype specificity-trade-offs in serodiagnosis of influenza A virus infections by competitive ELISA. JVirol Methods. 2011;173:49-59. https://doi.org/10. 1016/j.jviromet.2011.01.006

18. Dlugolenski D, Hauck R, Hogan RJ, Michel F, Mundt E. Production of $\mathrm{H} 5$-specific monoclonal antibodies and the development of a competitive enzyme-linked immunosorbent assay for detection of $\mathrm{H} 5$ antibodies in multiple species. Avian Dis. 2010;54:644-9. https://doi.org/10.1637/ 8683-030909-ResNote.1.

19. Jensen TH, Ajjouri G, Handberg KJ, Slomka MJ, Coward VJ, Cherbonnel M, Jestin V, Lind P, Jørgensen PH. An enzyme-linked immunosorbent assay for detection of avian influenza virus subtypes $\mathrm{H} 5$ and $\mathrm{H} 7$ antibodies. Acta Vet Scand. 2013;55:84. https://doi.org/10.1186/1751-0147-55-84.

20. Moreno A, Lelli D, Brocchi E, Sozzi E, Vinco LJ, Grilli G, Cordioli P. Monoclonal antibody-based ELISA for detection of antibodies against $\mathrm{H} 5$ avian influenza viruses. J Virol Methods. 2013;187:424-30. https://doi.org/10. 1016/j.jviromet.2012.11.006.

21. Desvaux S, Garcia JM, Nguyen TD, Reid SA, Bui NA, Roger F, Fenwick S, Peiris JS, Ellis T. Evaluation of serological tests for H5N1 avian influenza on field samples from domestic poultry populations in Vietnam: consequences for surveillance. Vet Microbiol. 2012;156:277-84. https://doi.org/ 10.1016/j.vetmic.2011.11.010.

22. Schmitz A, Le Bras MO, Guillemoto C, Pierre I, Rose N, Bougeard S, Jestin V. Evaluation of a commercial ELISA for $\mathrm{H} 5$ low pathogenic avian influenza virus antibody detection in duck sera using Bayesian methods. J Virol Methods. 2013;193:197-204. https://doi.org/10.1016/j.jviromet.2013.05. 002. 
23. Lebarbenchon C, Pantin-Jackwood M, Kistler WM, Luttrell MP, Spackman E, Stallknecht DE, Brown JD. Evaluation of a commercial enzymelinked immunosorbent assay for detection of antibodies against the $\mathrm{H} 5$ subtype of Influenza A virus in waterfowl. Influenza Other Respir Viruses. 2013;7:1237-40. https://doi.org/10.1111/irv.12070.

24. Kistler WM, Stallknecht DE, Lebarbenchon C, Pedersen K, Marks DR, Mickley R, DeLiberto TJ, Yabsley MJ. Influenza A virus H5-specific antibodies in mute swans (Cygnus olor) in the USA. J Wildl Dis. 2015;51:523-6. https:// doi.org/10.7589/2014-08-192

25. Jensen TH, Andersen JH, Hjulsager CK, Chriél M, Bertelsen MF. Evaluation of a commercial competitive enzyme-linked immunosorbent assay for detection of avian influenza virus subtype h5 antibodies in zoo birds. J Zoo Wildl Med. 2017;48:882-5. https://doi.org/10.1638/2016-0220.1.

26. Stelzer-Braid S, Wong B, Robertson P, Lynch GW, Laurie K, Shaw R, Barr I, Selleck PW, Baleriola C, Escott R, Katsoulotos G, Rawlinson WD. A commercial ELISA detects high levels of human $\mathrm{H} 5$ antibody but crossreacts with influenza A antibodies. J Clin Virol. 2008;43:241-3. https://doi. org/10.1016/j.jcv.2008.06.012.

27. World Organization for Animal Health. Manual of Diagnostic Tests and Vaccines for Terrestrial Animals 2018. Chapter 1.1.6. Principles and methods of validation of diagnostic assays for infectious diseases. https:// www.oie.int/fileadmin/Home/eng/Health_standards/tahm/1.01.06_ VALIDATION.pdf.

\section{Publisher's Note}

Springer Nature remains neutral with regard to jurisdictional claims in published maps and institutional affiliations.
Ready to submit your research? Choose BMC and benefit from:

- fast, convenient online submission

- thorough peer review by experienced researchers in your field

- rapid publication on acceptance

- support for research data, including large and complex data types

- gold Open Access which fosters wider collaboration and increased citations

- maximum visibility for your research: over 100M website views per year

At BMC, research is always in progress.

Learn more biomedcentral.com/submissions 